\title{
Effect of dilution of both A- and B- sites on the multiferroic properties of spinal Mott insulators
}

\author{
Prashant Shahi ${ }^{1}$, R. Singh ${ }^{1}$, Shiv Kumar ${ }^{2}$, A.Tiwari ${ }^{4}$, A.Tripathi ${ }^{4}$, J. Saha ${ }^{5}$, S. Patnaik ${ }^{5}$, A. K. \\ Ghosh $^{2}$ and Sandip Chatterjee ${ }^{1, *}$ \\ ${ }^{1}$ Department of Physics, Indian Institute of Technology (Banaras Hindu University), Varanasi- \\ 221005, India \\ ${ }^{2}$ Department of Physics, Banaras Hindu University, Varanasi-221 005, India \\ ${ }^{3}$ Department of Physics, National institute of Technology Durgapur, India \\ ${ }^{4}$ Department of Physical Sciences, School of Chemical and Physical Sciences, Sikkim \\ University, Sikkim, India \\ ${ }^{5}$ School of Physical Sciences, Jawaharlal Nehru University, New Delhi-110079, India
}

\begin{abstract}
The structural, magnetic, electrical and transport properties of $\mathrm{FeV}_{2} \mathrm{O}_{4}$, by doping $\mathrm{Li}$ and $\mathrm{Cr}$ ions respectively in A and B sites, have been studied. Dilution of A-site by Li doping increases the ferri-magnetic ordering temperature and decreases the ferroelectric transition temperature. This also decreases the $\mathrm{V}-\mathrm{V}$ distances which in effect increases the A-V coupling. This increased A-V coupling dominates over the decrease in A-V coupling due to doping of non-magnetic Li. On the other hand, $\mathrm{Cr}$ doping increases the ferri-magnetic ordering temperature but does not alter the ferroelectric transition temperature which is due to the fact that the polarization origin to the presence of almost non-substituted regions.
\end{abstract}

*Corresponding author $e$-mail id: schatterji.app@iitbhu.ac.in

Ph.No. \& Fax No.: +91-5426701913 


\section{Introduction}

Transition- metal- oxide (TMO) spinals are becoming the centre of attraction with significant quality of complex interaction among charge, spin and orbital degrees of freedom which gives it some interesting properties. Importantly, vanadium spinel oxides $\mathrm{AV}_{2} \mathrm{O}_{4}(\mathrm{~A}$ $=\mathrm{Fe}^{2+}, \mathrm{Mn}^{2+}, \mathrm{Co}^{2+}, \mathrm{Zn}^{2+}, \mathrm{Mg}^{2+}$ ), where $\mathrm{A}^{2+}$ and $\mathrm{V}^{3+}$ ions occupy the tetrahedral (A site) and octahedral (B site) sites, respectively, have two $3 \mathrm{~d}$ electrons in the triply degenerate $\mathrm{t}_{2 \mathrm{~g}}$ states at $\mathrm{V}^{3+}$ site. This whole arrangement is becoming the centre of attention because of their fascinating magnetic and orbital order. ${ }^{1-7}$ When A site is replaced by some non magnetic ion [ $\mathrm{Li}, \mathrm{Zn}, \mathrm{Mg}$, $\mathrm{Cd}$ ] it shows many interesting properties. Likewise $\mathrm{ZnV}_{2} \mathrm{O}_{4}$ goes from cubic to tetragonal state at $\mathrm{T}=50 \mathrm{~K}$ and orders antiferromagnetically at $\mathrm{T}=42 \mathrm{~K}^{8}$ and $\mathrm{LiV}_{2} \mathrm{O}_{4}$ shows metallic behavior and it is a first transition metal oxide which shows heavy fermion behavior and remains in cubic phase in its whole temperature range. ${ }^{9-11}$ On the other hand, when A site is replaced by Magnetic ions, different properties emerges. In this way the $\mathrm{MnV}_{2} \mathrm{O}_{4}$ exempts magnetic phase transition from the collinear ferrimagnetic order to the non-collinear canted one at $53 \mathrm{~K}$ with associations to the anti-ferro-orbital order of vanadium $\mathrm{t}_{2 \mathrm{~g}}$ orbitals. ${ }^{3,12}$ Whereas, $\mathrm{CoV}_{2} \mathrm{O}_{4}$ exhibits two magnetic phase transitions at $142 \mathrm{~K}$ and $59 \mathrm{~K}$ without any structural phase transitions. ${ }^{13,14}$

Moreover, $\mathrm{FeV}_{2} \mathrm{O}_{4}$ is a unique compound among such spinel vandium oxides comprising both $\mathrm{Fe}^{2+}$ and $\mathrm{V}^{3+}$ ions with orbital degrees of freedom; $\mathrm{Fe}^{2+}$ ion at the tetrahedral site (A-site) having three $3 \mathrm{~d}$ electrons in the doubly degenerate $e_{g}$ states. Very recent development shows structural and magnetic properties of the spinal $\mathrm{FeV}_{2} \mathrm{O}_{4}$ [11] exhibiting successive structural transitions from cubic to compressed tetragonal with the lattice constants of $c<a$ at $T \mathrm{~s}_{1} \sim 140 \mathrm{~K}$ which is due to the cooperative Jahn-Teller effect of $\mathrm{FeO}_{4}$ and from tetragonal to orthorhombic transition accompanied by a ferrimagnetic transition at $T_{\mathrm{s} 2} \sim 110 \mathrm{~K}$, and from orthorhombic to elongated tetragonal with $c>a$ at $T_{\mathrm{s} 3} \sim 60 \mathrm{~K}$ with decreasing temperature for polycrystalline samples. It has also been reported that the Jahn-Teller effects and the relativistic spin-orbital coupling play an important role in the determination of the orbital states of $\mathrm{Fe}^{2+}$ and $\mathrm{V}^{3+}$ ions at low temperatures which were concluded with the help of single crystal $\mathrm{x}$ ray diffraction experiments. ${ }^{6}$ Recent reports of NMR and neutron diffraction of $\mathrm{FeV}_{2} \mathrm{O}_{4}$ indicate that its structure is changing to non-collinear ferrimagnetic state at $60 \mathrm{~K}$ from collinear state, where the $\mathrm{V}^{3+}$ moments become mounted along the $\{111\}$ directions. ${ }^{7,15}$ This latter transition is marked by 
a step in magnetization, a peak in heat capacity, an anomaly in the dielectric constant, and the appearance of polarization. It was found that the application of a magnetic field shifts all these signatures associated to $\mathrm{T}_{\mathrm{s} 3}$ to higher temperatures, while it also clearly affects the value of the polarization, revealing a significant magneto electric coupling. It is suggested that the presence of canted spins in the triangular structure below $\mathrm{T}_{\mathrm{s} 3}$ could be responsible for the appearance of ferroelectricity. ${ }^{16}$

The $\mathrm{AV}_{2} \mathrm{O}_{4}$ system also approaches the itinerant-electron limit with decreasing $\mathrm{V}-\mathrm{V}$ separation. ${ }^{17-18}$ The predicted critical separation for metallic behavior is $R_{c}=2.94 \AA .{ }^{19}$ A Recent study on $\mathrm{FeV}_{2} \mathrm{O}_{4}$ and $\mathrm{CoV}_{2} \mathrm{O}_{4}$ shows that with increasing pressure the $\mathrm{V}-\mathrm{V}$ separation decreases and due to which there is a delocalization of charge carriers in $\mathrm{FeV}_{2} \mathrm{O}_{4}$ and it induces metallic behavior in $\mathrm{CoV}_{2} \mathrm{O}_{4}{ }^{14}$ The same effect is also shown by chemical pressure by doping Co at the site of $\mathrm{MnV}_{2} \mathrm{O}_{4}{ }^{20}$ Recently it is shown that in $\mathrm{FeV}_{2} \mathrm{O} 4, \mathrm{CoV}_{2} \mathrm{O}_{4}$ and $\mathrm{MnV}_{2} \mathrm{O}_{4}$ the magnetic transition temperature suppressed and activation energy decreases as $\mathrm{Zn}^{2+}$ (non magnetic ion) doped at the A site. ${ }^{21-23}$ Furthermore, $\mathrm{Li}^{1+}$ is also a non magnetic ion and its size is comparable to $\mathrm{Mn}, \mathrm{Zn}, \mathrm{Fe}$ and $\mathrm{Co}$ but $\mathrm{Li}^{1+}$ has no 3d electron in their outer shell unlike Fe and Co. Therefore, it will be interesting to investigate the magnetic and transport properties by doping $\mathrm{Li}$ in $\mathrm{CoV}_{2} \mathrm{O}_{4}$ and $\mathrm{FeV}_{2} \mathrm{O}_{4}$ at the $\mathrm{A}$ site.

Furthermore, soft magnetic materials are center to nearly every aspect of modern electrical and electronics technology because of their ability to concentrate and to shape magnetic flux with great efficiency. The most important characteristics desired for essentially all soft magnetic applications are high saturation induction, high permeability, low coercivity, and low core loss. In this regard these materials are highly important from the application point of view.

In this paper, we have investigated magnetic, electrical polarization and transport properties of $\mathrm{Li}_{\mathrm{x}} \mathrm{Fe}_{1-\mathrm{x}} \mathrm{V}_{2} \mathrm{O}_{4}(0 \leq \mathrm{x} \leq 0.1)$ and found that with increasing the $\mathrm{Li}$ and $\mathrm{Cr}$ content at $\mathrm{Fe}(\mathrm{A})$ and $\mathrm{V}$ (B) sites the Ferrimagnetic transition temperature increases, electric polarization temperature remains same with $\mathrm{Cr}$ doping and decreases for Li doping and the system moves towards iterant electron limit due to decrease in the $\mathrm{V}-\mathrm{V}$ distance with Li doping and moves towards more localized behaviour with Cr doping . 


\section{Experiment}

The polycrystalline $\mathrm{Fe}\left(\mathrm{V}_{1-\mathrm{x}} \mathrm{Cr}_{\mathrm{x}}\right)_{2} \mathrm{O}_{4}(0 \leq \mathrm{x} \leq 0.05)$ and $\mathrm{Li}_{\mathrm{x}} \mathrm{Fe}_{1-\mathrm{x}} \mathrm{V}_{2} \mathrm{O}_{4}(0 \leq \mathrm{x} \leq 0.1)$ samples used in this study were prepared by solid state reaction method. Appropriate ratio of $\mathrm{Li}_{3} \mathrm{VO}_{4}, \mathrm{Fe}, \mathrm{Fe}_{2} \mathrm{O}_{3}$, $\mathrm{Cr}_{2} \mathrm{O}_{3}, \mathrm{~V}_{2} \mathrm{O}_{3}$ and $\mathrm{V}_{2} \mathrm{O}_{5}$ were grounded thoroughly and pressed into pellets. The pellets were sealed in evacuated quartz tube and heated at $1050^{\circ} \mathrm{C}$ for 40 hours for $\mathrm{Li}_{\mathrm{x}} \mathrm{Fe}_{1-\mathrm{x}} \mathrm{V}_{2} \mathrm{O}_{4}(0 \leq \mathrm{x} \leq 0.1)$. The X-ray powder diffraction experiment has been performed using Rigaku Mini Flex II DEXTOP X-ray Diffractometer with $\mathrm{Cu}-\mathrm{k} \alpha$ radiation. Magnetic measurement was done using MPMS SQUID (Quantum Design) magnetometer with the bulk samples. Ac-susceptibility measurement were done using lock in amplifier SRS830 by homemade setup and standardized with YBCO superconducting sample. The electric polarization $(\mathrm{P})$ as a function of temperature was determined by integrating the pyroelectric current measured on warming at a rate of $5 \mathrm{~K} / \mathrm{min}$ with a Keithley 6517A electrometer then cooled with a poling electric field of $640 \mathrm{kV} / \mathrm{m}$ applied from $90 \mathrm{~K}$ to $6 \mathrm{~K}$. At $6 \mathrm{~K}$, the poling electric field was removed and the electrodes were shortened for $1 \mathrm{~h}$ to reduce the possible contribution from the detrapped charges. Resistivity measurements have been done using four probe method.

\section{Results and Discussions}

Figure 1 shows the X-ray diffraction (XRD) pattern for different Li and $\mathrm{Cr}$ doped samples. All peaks are indexed with Fd-3m space group indicating our samples are of pure phase. Inset of the figure 1 shows variation of lattice parameter with $\mathrm{Li}$ and $\mathrm{Cr}$ Doping, obtained from the Rietveld refinement of the XRD data. It is observed that with increasing the Li concentration at the Fe site the lattice parameters decrease linearly following the Vegard's law. The same trend is followed by $\mathrm{Cr}$ doping also. The ionic size of $\mathrm{Li}$ is $0.73 \AA$ which is smaller than $\mathrm{Fe}(0.77 \AA)$ and $\mathrm{V}^{3+}$ ionic size is $0.78 \AA$ is greater then $\mathrm{Cr}^{3+}(0.75 \AA)$ ionic radius. As a matter of fact, the lattice parameters decrease with $\mathrm{Li}$ and $\mathrm{Cr}$ doping. In case of Li doping the lattice parameter decreases very sharply with respect to $\mathrm{Cr}$ doping which might be due to the fact that in $\mathrm{Li}$ no $3 \mathrm{~d}$ electrons present in outer shell due to which the Coulomb repulsion decreases between Li/Fe and oxygen $2 p$ electrons. The parameters obtained from Reitveld refinement are given in the Table 1. Figure 2 shows the variation of $\mathrm{ZFC}$ and $\mathrm{FC}$ magnetization with temperature for $\mathrm{Li}_{\mathrm{x}} \mathrm{Fe}_{1-\mathrm{x}} \mathrm{V}_{2} \mathrm{O}_{4}(0 \leq \mathrm{x} \leq 1)$ and $\mathrm{Fe}\left(\mathrm{V}_{1-\mathrm{x}} \mathrm{Cr}_{\mathrm{x}}\right)_{2} \mathrm{O}_{4} \quad(0 \leq \mathrm{x} \leq 0.05)$. For $\mathrm{FeV}_{2} \mathrm{O}_{4}$ (Fig. 2(a)), with decrease of temperature, a 
transition from paramagnetic (PM) to ferrimagnetic (FI) phase occurs below Tc. ZFC magnetization bifurcates from FC magnetization around $112 \mathrm{~K}$, then decreases with further decreasing temperature. A small rise in FC curve exists at a lower temperature Tp, accompanied by a slight drop in ZFC magnetization. This magnetization behavior is consistent with that already reported. ${ }^{24}$ The values of Tc and Tp determined from the dM/dT vs. T curve of the FC magnetization, are $112 \mathrm{~K}$ and $62 \mathrm{~K}$, respectively. With $\mathrm{Li} 10 \%$ doping the $\mathrm{T}_{\mathrm{C}}$ increase to $126 \mathrm{~K}$ but the $\mathrm{T}_{\mathrm{P}}$ disappears whereas for $5 \% \mathrm{Cr}$ doping $\mathrm{T}_{\mathrm{C}}$ increaess to $120 \mathrm{~K}$ but $\mathrm{T}_{\mathrm{P}}$ remains unchanged. We have also measured ac-susceptibility at $100 \mathrm{~Hz}$ for $\mathrm{Li}_{\mathrm{x}} \mathrm{Fe}_{1-\mathrm{x}} \mathrm{V}_{2} \mathrm{O}_{4}(0 \leq \mathrm{x} \leq 1)$ which is shown in figure 3. Similar behavior is observed that with increasing Li content at A site the ferrimagnetic transition temperatures increase. This might be due to the fact that shrinkage of the lattice parameter with $\mathrm{Li}$ and $\mathrm{Cr}$ doping, increases the exchange interaction between the $\mathrm{A}^{2+}$ and $\mathrm{V}^{3+}$ through oxygen which enhances the ferrimagnetic ordering temperature.

Figure 4 shows the $\mathrm{M}(\mathrm{H})$ curve at $2 \mathrm{~K}$ for undoped and $\mathrm{Li}$ and $\mathrm{Cr}$ doped samples. For the undoped sample a jump at $\sim 0 \mathrm{~T}$ and another jump $\sim 1.25 \mathrm{~T}$ are observed which are consistent with that reported by Nishihara et. $\mathrm{Al} .{ }^{24}$ But when Li is doped the jumps disappear. On the other hand when $\mathrm{Cr}$ is doped the 0T jump shifts to $1.0 \mathrm{~T}$ and the $1.25 \mathrm{~T}$ jump shifts to $1.3 \mathrm{~T}$ and an extra jump is observed at $\sim 2.5 \mathrm{~T}$. In their paper. ${ }^{24}$ Nishihara et al explained the $1.2 \mathrm{~T}$ jump in $\mathrm{FeV}_{2} \mathrm{O}_{4}$ as the avalanche behavior. ${ }^{25}$ But the origin of jumps in $\mathrm{Cr}$ doped sample are not yet clear. It might be due to some Martensitic transition. ${ }^{26}$ Anyway, it deserves further study. On the other hand, the saturated moment, estimated from figure 4, decreases upon Li doping and increases for $\mathrm{Cr}$ doping. Since Li ions are non-magnetic and $\mathrm{Cr}$ ions are more magnetic than $\mathrm{V}$ ions and it is known that $\mathrm{V}$ spins tend to align anti-parallel to each other when the coupling between $\mathrm{A}$ and $\mathrm{B}$ sub-lattices is absent. Therefore, the moment of the V sub-lattice also decreases with increasing $\mathrm{Li}$ content and increases for $\mathrm{Cr}$ content. It is important to compare these with the earlier studies on $\mathrm{Zn}_{\mathrm{x}} \mathrm{Mn}_{1-\mathrm{x}} \mathrm{V}_{2} \mathrm{O}_{4}$ [23] and $\mathrm{Co}_{1-\mathrm{x}} \mathrm{Zn}_{\mathrm{x}} \mathrm{V}_{2} \mathrm{O}_{4}$ [22] because $\mathrm{Zn}(0.74 \AA)$ is also a non magnetic ion. Moreover, the sizes of $\mathrm{Li}(0.73 \AA)$, Co $(0.72 \AA)$ and $\mathrm{Zn}(0.74 \AA)$ are comparable. In case of $\mathrm{Zn}_{\mathrm{x}} \mathrm{Mn}_{1-\mathrm{x}} \mathrm{V}_{2} \mathrm{O}_{4}$ it is found that as the $\mathrm{Zn}$ content increases the magnetic transition temperature decreases which is different than that in Li doped samples. With Zn doping two cases arises, the lattice parameters decrease with increasing $\mathrm{Zn}$ content due to which the $\mathrm{V}-\mathrm{V}$ distance decreases so that coupling between $\mathrm{A}$ and $\mathrm{V}$ sites increase which tries to increase the magnetic transition 
temperature. But doping of non magnetic ion at A site decreases the A-V coupling due to which $\mathrm{V}-\mathrm{V}$ spins try to align anti-parallel. As a result, the magnetic transition is suppressed. ${ }^{23}$

Figure 5 shows the temperature dependent electrical polarization for the $\mathrm{FeV}_{2} \mathrm{O}_{4}$, $\mathrm{Li}_{0.05} \mathrm{Fe}_{0.95} \mathrm{~V}_{2} \mathrm{O}_{4}$ and $\mathrm{Fe}\left(\mathrm{Cr}_{0.05} \mathrm{~V}_{0.95}\right)_{2} \mathrm{O}_{4}$ samples. The electrical polarization (P) appears at about $\mathrm{T}_{\mathrm{p}}=61 \mathrm{~K}$ for $\mathrm{FeV}_{2} \mathrm{O}_{4}$ and $38 \mathrm{~K}$ for $\mathrm{Li}_{0.05} \mathrm{Fe}_{0.95} \mathrm{~V}_{2} \mathrm{O}_{4}$ and approaching a saturated value with decreasing temperature. For $10 \% \mathrm{Li}$ doping no polarization is observed consistent with the magnetization behavior. With $\mathrm{Li}$ doping, also the onset temperature decreases. This result emphasizes that this substituted $\mathrm{FeV}_{2} \mathrm{O}_{4}$ remains a multiferroic until dilution becomes too detrimental to the magnetic ordering. But with $\mathrm{Cr}$ doping the onset temperature remains same. In contrast, for the $\mathrm{Cr}$ doped samples $\left(\mathrm{Fe}\left(\mathrm{Cr}_{0.05} \mathrm{~V}_{0.95}\right)_{2} \mathrm{O}_{4}\right)$, the $P(T)$ curves reveal unchanged $T_{P}$ values as $x$ increases. The temperature, $T_{P}$ (ferroelectric transition temperature), is not changing with $\mathrm{Cr}$ content, but the $\mathrm{P}$ value decreases with increase of $\mathrm{Cr}$ content. It is thus reasonable to ascribe the polarization origin to the presence of almost non-substituted regions (with compositions near $\mathrm{FeV}_{2} \mathrm{O}_{4}$ and whose amount decreases with increasing $x$ ). From above discussion it is clear that Li doping suppresses the collinear to non collinear state but Cr doping does not change the collinear state to non collinear state, which might be due to the fact that with $\mathrm{Li}$ doping the coupling between $\mathrm{V}-\mathrm{V}$ decreases due to the presence of $\mathrm{V}^{3+}$ and $\mathrm{V}^{4+}$ at the octahedral site but $\mathrm{Cr} 5 \%$ doping has no effect on $\mathrm{V}-\mathrm{V}$ coupling which in effect does not change the onset temperature.

Figure 6(a) shows the variation of resistivity with temperature for all the samples and Figure 6(b) shows the $\ln \rho$ vs 1000/T for $\mathrm{Fe}_{1-\mathrm{x}} \mathrm{Li}_{\mathrm{x}} \mathrm{V}_{2} \mathrm{O}_{4}$ [where $\mathrm{x}=0$ and 0.1] and $\mathrm{Fe}\left(\mathrm{Cr}_{0.05} \mathrm{~V}_{0.95}\right)_{2} \mathrm{O}_{4}$ [where $\mathrm{x}=0.05$ ]. As $\mathrm{FeV}_{2} \mathrm{O}_{4}$ belongs to Mott Insulator regime therefore from the figure it can be mentioned that with increasing $\mathrm{Li}$ content at the A site the system moves towards itinerant electron side along with the decrease of $\mathrm{V}-\mathrm{V}$ distance. The $3 d$ electrons in $\mathrm{Cr}$ ions are well localized. Therefore, in the Cr-doped samples the electric resistivity shows an insulating behavior.

\section{Conclusion}

The structural, magnetic, electrical and transport properties of $\mathrm{FeV}_{2} \mathrm{O}_{4}$, by diluting A-site by $\mathrm{Li}$ and B-site by $\mathrm{Cr}$, have been studied. It is observed that increasing the Li content at A site the V$\mathrm{V}$ distance decreases and due to that ferrimagnetic ordering temperature increases while the 
ferroelectric transition temperature decreases and the whole system moves towards the itenerant electron behavior. In the case of $\mathrm{Cr}$ doping the magnetic transition temperature increases but there is no effect on the ferroelectric transition temperature and the system moves towards more inside the Mott insulating region. So by tuning the V-V distance either by external pressure or chemical pressure we can tune the magnetic, ferroelectric and transport properties or more specifically, the multiferroic properties of Mott-insulating $\mathrm{FeV}_{2} \mathrm{O}_{4}$ which is very important from the application point of view.

\section{Acknowledgement}

SC is grateful to DST, India (Grant No.: SR/S2/CMP-26/2008), CSIR, India (Grant No.: 03(1142)/09/EMR-II) and BRNS, DAE, India ((Grant No.: 2013/37P/43/BRNS) for providing financial support. PS is grateful to CSIR, India for providing financial support.

\section{References:}

[1] M. Wheeler, B.Lake, I. A .T. M. Nazmul, M Reehuis., P. Steffens, T. Guidi and A. H. Hill 2010 Phys. Rev. B 82140406.

[2] S. H. Lee et al 2004 Phys. Rev. Lett. 93156407.

[3] T. Suzuki, M. Katsumura, K. Taniguchi, T. Arima and T. Katsufuji 2007 Phys. Rev. Lett. 98 127203.

[4] T. Katsufuji, T. Suzuki, H. Takei, M.Shingu, K. Kato , K. Osak, M. Takata, H. Sagayama and T. Arima 2008 J. Phys. Soc. Japan 77053708.

[5] S. Sakar, T. Maita, R. Valenti and T. Saha-Dasgupta 2009 Phys. Rev. Lett.102 216405.

[6] Nii Yet al 2012 Phys. Rev. B 86125142.

[7] G. J. MacDougall, V. O. Garlea, A .A. Aczel, H. D . Zhou and S .E. Nagler 2012 Phys. Rev.B 86060414.

[8] Y. Ueda, N. Fujiwara and H. Yasuoka 1997 J. Phys. Soc. Jpn. 66778.

[9] S. Kondo, D .C. Johnston, C .A .Swenson, F. Borsa, A. V. Mahajan, L. L. Miller, T. Gu, A. I. Goldman, M .B. Maple, D. A. Gajewski, E. J. Freeman, N. R. Dilley, R. P. Dickey, J. Merrin, K. Kojima, G .M. Luke, Y. J. Uemura, O. Chmaissem and J. D. Jorgensen 1997 Phys. Rev. Lett., 78 3279 . 
[10] P. W . Anderson 1956 Phys. Rev. 1021008.

[11] D. C. Johnston, C .A. Swenson and S. Kondo 1999 Phys. Rev. B 592627.

[13] Y. Huang, Z. Yang and Y. Zhang, unpublished

[14] A. Kismarahardja, J. S. Brooks, A. Kiswandhi, K. Matsubayashi, R. Yamanaka, Y. Uwatoko, J. Whalen, T. Siegrist and H. D. Zhou 2011 Phys. Rev. Lett.106 056602.

[15] T. Katsufuji, T. Suzuki, H. Takei, M. Shingu, K. Kato, K. Osaka, M. Takata, H . Sagayama and T. Arima 2008 J. Phys. Soc. Jpn. 77053708.

[16] N. Liu, K.H. Zhao, X.L. Shi and L. Zhang W 2012 J. App. Phys. 111124112.

[17] D.B. Rogers et al 1963 J. Phys. Chem. Solids 24347.

[18] D.B.Rogers et al 1964 J. Appl. Phys. 351069 .

[19] J.B.Goodenough 1972in Metallic Oxides, edited by Reiss H, Progress in Solid State Chemistry (Pergamon, New York, 1972), Vol. 5.

[20] A.Kiswandhi, J.S.Brooks,J. Lu, J .Whalen, T. Siegrist and H.D. Zhou 2011 Phys. Rev. B 84 205138.

[21] H. Ishibashi and Y. Kitadai 2012 Journal of Physics: Conference Series 391012092.

[22] Y. Huang, L. Pi, S. Tan,Z. Yang and Y. Zhang 2012 J. Phys.: Condens. Matter 24056001.

[23] P. Shahi, S. Kumar, N.Sharma,R. Singh, P.U. Sastry,A. Das,A. Kumar,K.K. Shukla,A.K.

Ghosh, A.K.Nigam and S. Chatterjee 2014 J Mater Sci 49 7317-7324.

[24] S .Nishihara, W. Doi, H. Ishibashi, Y.Hosokoshi, Xiao-Ming Ren and Shigeo Mori J. App. Phys.107,09A504(2010)

[25] K. Takeda, K. Awaga, T. Inabe, N. Môri, and H. Nojiri, Phys. Rev. B 65,094424 (2002)

[26] S. Taran, B. K. Chaudhuri, A. Das, A. K. Nigam, R. K. Kremer, and S. Chatterjee, J. Phys.: Condens. Matter 19, 216217 (2007) 
Table 1. Structural parameters (lattice parameters, bond lengths) of $\mathrm{Fe}_{1-\mathrm{x}} \mathrm{Li}_{\mathrm{x}} \mathrm{V}_{2} \mathrm{O}_{4}(0<\mathrm{x}<0.1)$ ) samples obtained from Rietveld refinement of X-ray diffraction data

\begin{tabular}{|c|c|c|}
\hline Sample Name & $\mathrm{a}(\AA)$ & $\mathrm{d}(\mathrm{V}-\mathrm{V})\left(\mathrm{A}^{0}\right)$ \\
\hline $\mathrm{FeV}_{2} \mathrm{O}_{4}$ & 8.4517 & 2.9881 \\
\hline $\mathrm{Fe}_{0.95} \mathrm{Li}_{0.05} \mathrm{~V}_{2} \mathrm{O}_{4}$ & 8.4429 & 2.9850 \\
\hline $\mathrm{Fe}_{0.9} \mathrm{Li}_{0.1} \mathrm{~V}_{2} \mathrm{O}_{4}$ & 8.4341 & 2.9819 \\
\hline $\mathrm{Fe}\left(\mathrm{Cr}_{0.05} \mathrm{~V}_{0.95}\right)_{2} \mathrm{O}_{4}$ & 8.4485 & 2.9870 \\
\hline
\end{tabular}

\section{Figure Captions:}

1. X-ray diffraction pattern with Reitveld refinement for $\mathrm{Li}$ and $\mathrm{Cr}$ doped $\mathrm{FeV}_{2} \mathrm{O}_{4}$ samples at $300 \mathrm{~K}$. The inset shows the variation of lattice parameters with $\mathrm{Li}$ and $\mathrm{Cr}$ concentration

2. Temperature variation of magnetization for $\mathrm{Fe}_{1-\mathrm{x}} \mathrm{Li}_{\mathrm{x}} \mathrm{V}_{2} \mathrm{O}_{4}$ [where $\mathrm{x}=0,0.05$, and 0.1 spinels .at $\mathrm{H}=5000 \mathrm{Oe}$ ] and $\mathrm{Fe}\left(\mathrm{Cr}_{0.05} \mathrm{~V}_{0.95}\right)_{2} \mathrm{O}_{4}$ [where $\mathrm{x}=0$ and 0.05 spinels .at $\mathrm{H}=5000 \mathrm{Oe}$ ] and. Inset shows the plot of $\mathrm{dM} / \mathrm{d} \mathrm{T}$ vs.T indicating transitions.

3. Temperature dependence of AC magnetization measured in fields with $100 \mathrm{~Hz}$ frequency for $\mathrm{Fe}_{1-\mathrm{x}} \mathrm{Li}_{\mathrm{x}} \mathrm{V}_{2} \mathrm{O}_{4}$ [where $\mathrm{x}=0,0.05$, and 0.1 ] around $\mathrm{T}_{\mathrm{C}}$. Inset shows the Variation of $\mathrm{T}_{\mathrm{C}}$ with respect to $1 / \mathrm{R}_{\mathrm{V}-\mathrm{V}}$.

4. The isothermal field dependence of the magnetization at $2 \mathrm{~K}$ for $\mathrm{Fe}_{1-\mathrm{x}} \mathrm{Li}_{\mathrm{x}} \mathrm{V}_{2} \mathrm{O}_{4}$ [where $\mathrm{x}=0$ and 0.01 ] and $\mathrm{Fe}\left(\mathrm{Cr}_{0.05} \mathrm{~V}_{0.95}\right)_{2} \mathrm{O}_{4}$ [where $\left.\mathrm{x}=0.05\right]$.

5. The temperature dependence of ferroelectric polarizaiton of $\mathrm{Li}$ and $\mathrm{Cr}$ doped FeV2O4

6. (a)The temperature dependences of resistivity for $\mathrm{Fe}_{1-\mathrm{x}} \mathrm{Li}_{\mathrm{x}} \mathrm{V}_{2} \mathrm{O}_{4}$ [where $\mathrm{x}=0$ and 0.01 ] and $\mathrm{Fe}\left(\mathrm{Cr}_{0.05} \mathrm{~V}_{0.95}\right)_{2} \mathrm{O}_{4}$ [where $\mathrm{x}=0.05$ ] (b) $\ln \rho$ vs $1000 / \mathrm{T}$ for $\mathrm{Fe}_{1-\mathrm{x}} \mathrm{Li}_{\mathrm{x}} \mathrm{V}_{2} \mathrm{O}_{4}$ [where $\mathrm{x}=0$ and 0.01 ] and $\mathrm{Fe}\left(\mathrm{Cr}_{0.05} \mathrm{~V}_{0.95}\right)_{2} \mathrm{O}_{4}[$ where $\mathrm{x}=0.05]$. 


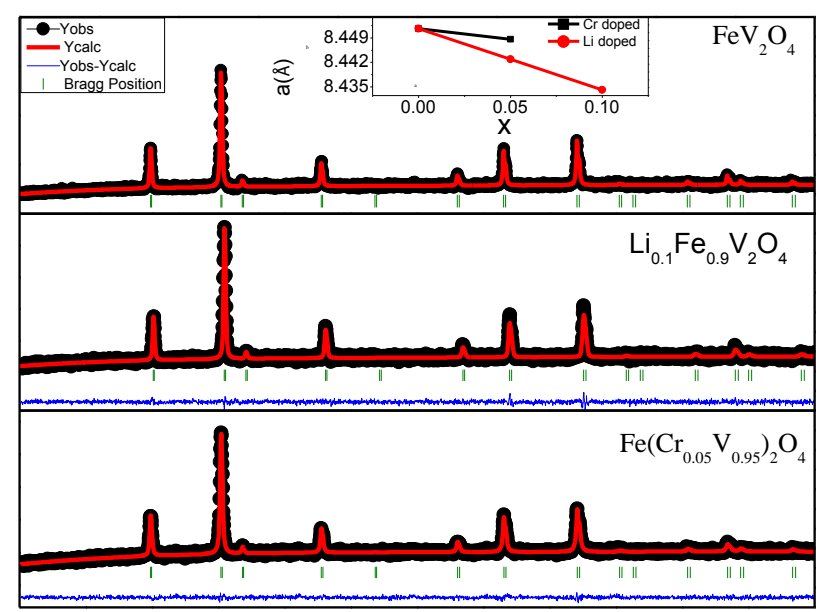

Figure 1 


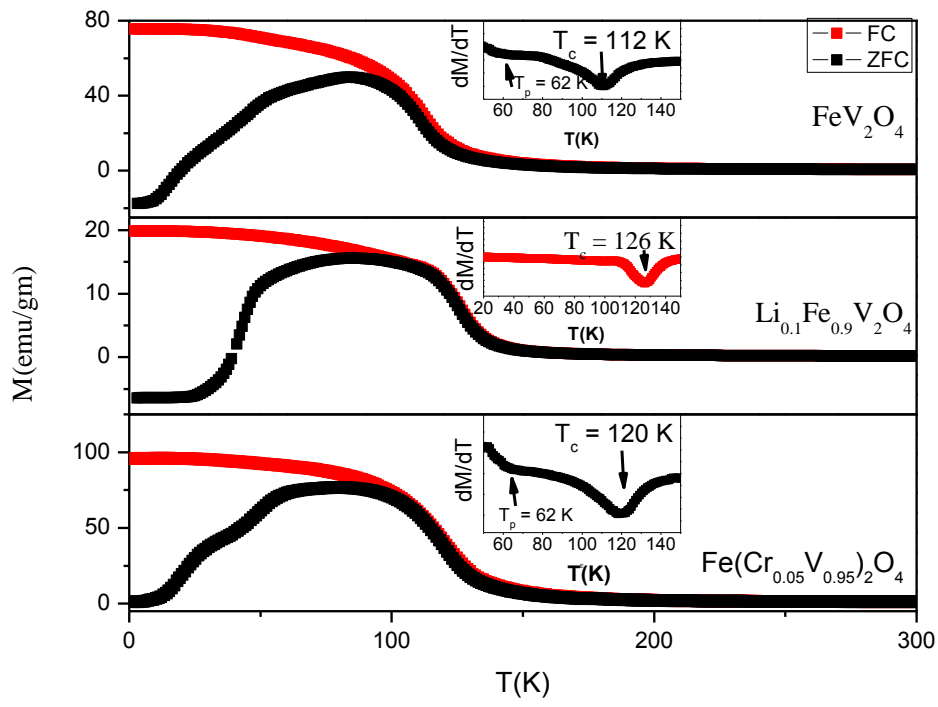

Figure 2

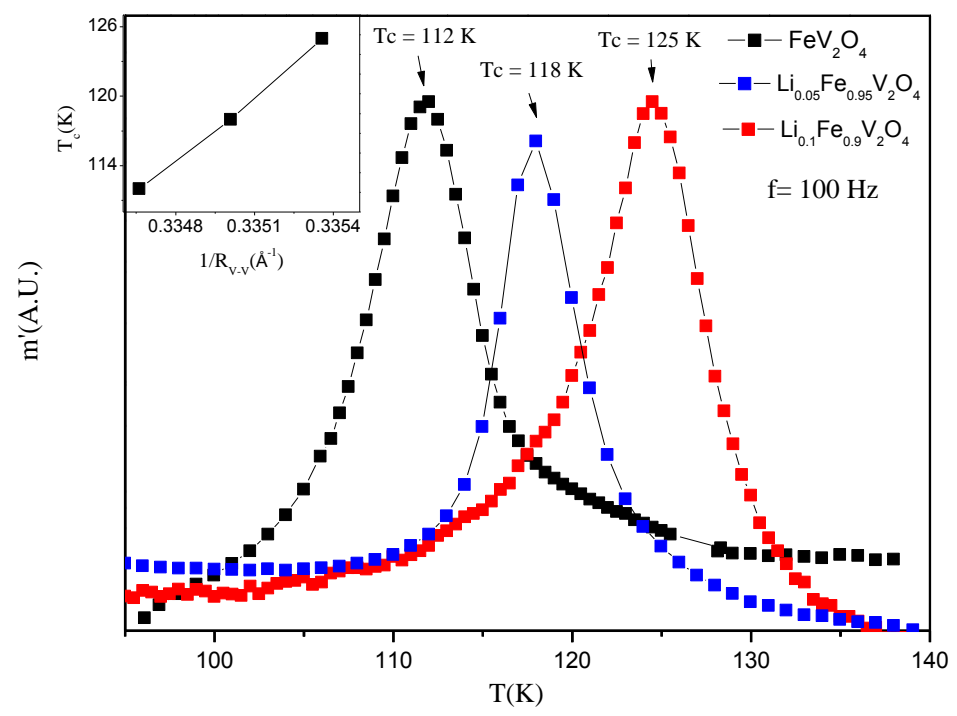

Figure 3 


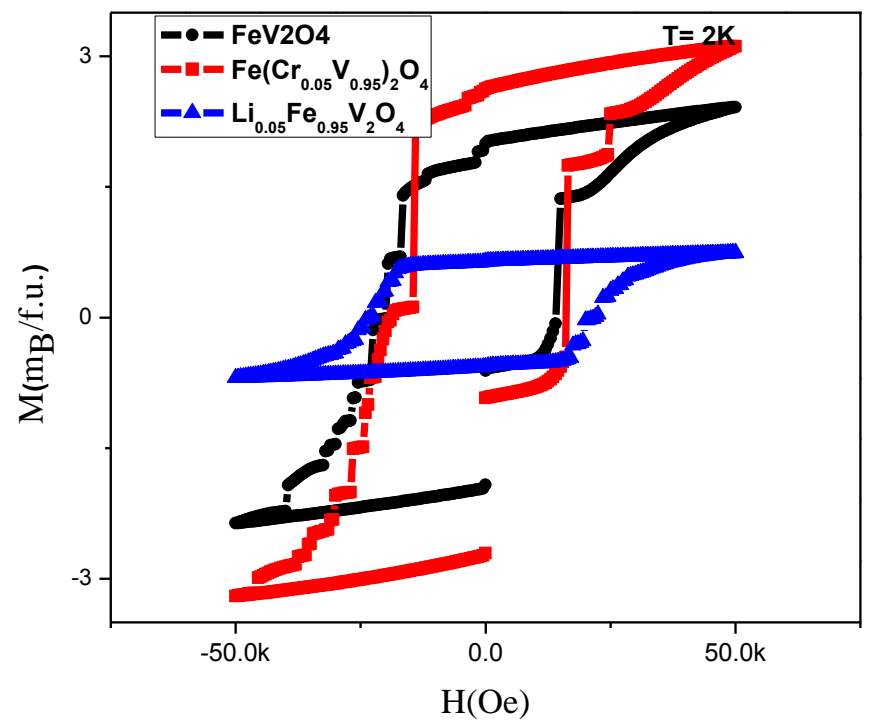

Figure 4

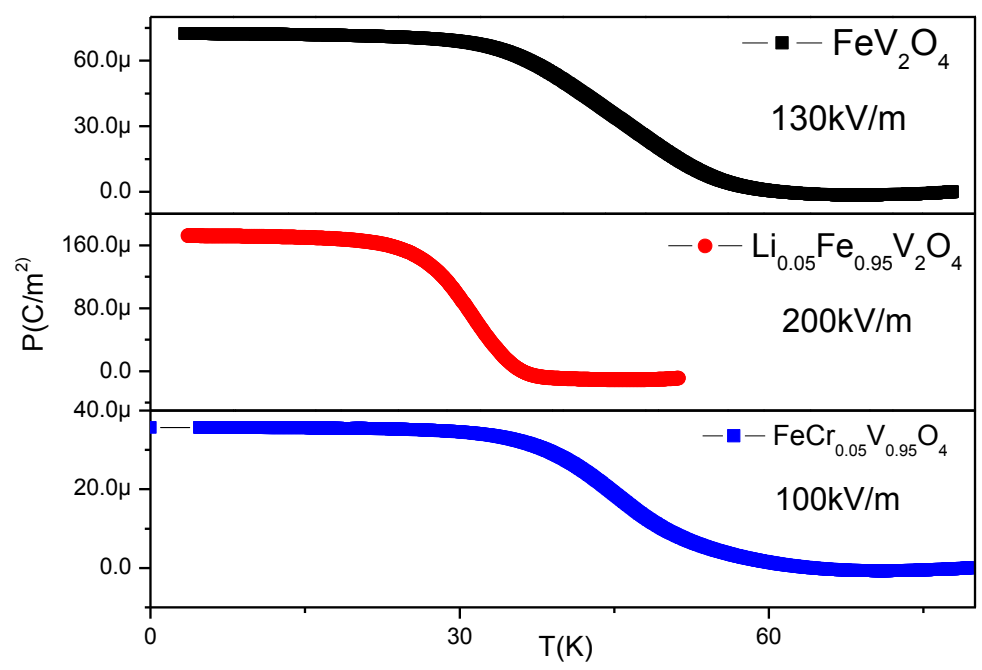

Figure 5 

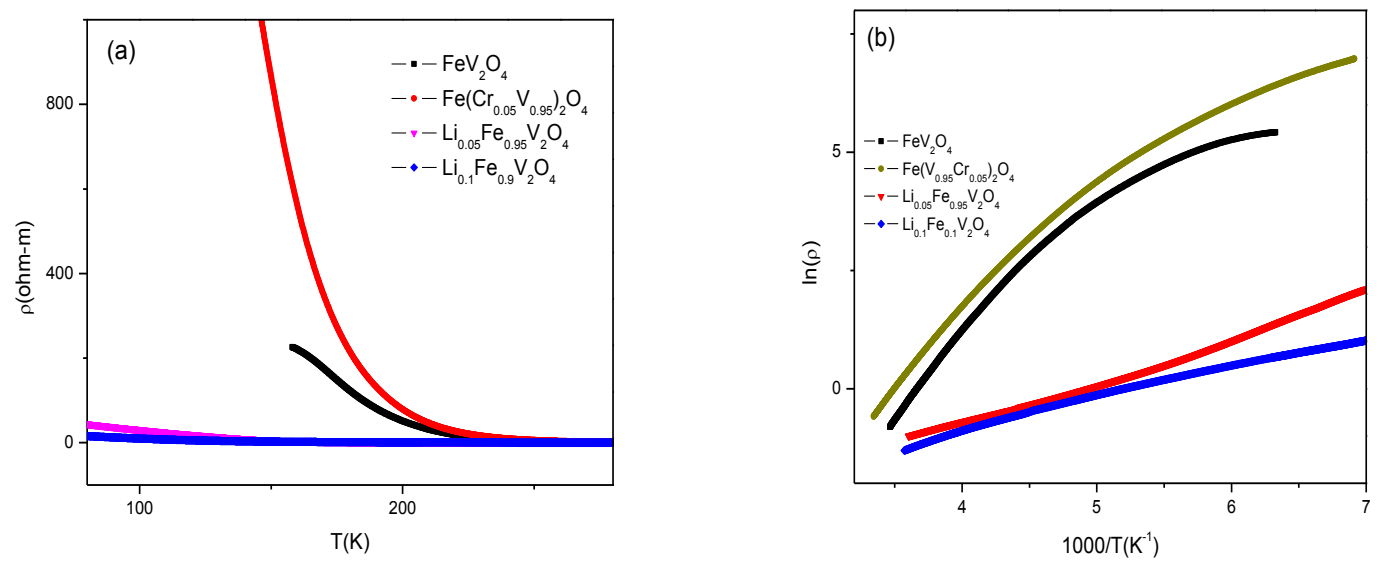

Figure 6 